\title{
Rectal tonsil: a rare cause of rectal bleeding
}

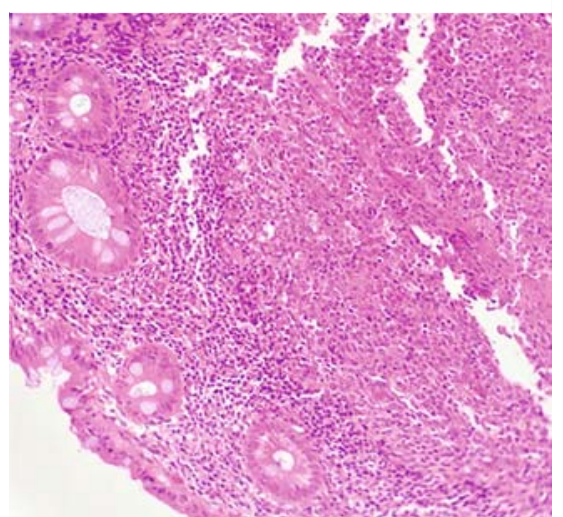

Fig. 1 Rectal mucosa of a 21-year-old patient with a 4-month history of rectal bleeding. Lymphatic follicle with a prominent germinal center containing tingible body macrophages (H\&E, × 10).

A rectal tonsil is a lymphoid follicular hyperplasia of the rectum and a rare cause of rectal bleeding. As it is a benign lesion of uncertain etiology [1,2], treatment is reserved for symptomatic patients [2].

We present the case of a 21-year-old woman with normal bowel movements who presented with a history of rectal bleeding over a period of 4 months. Digital rectal examination revealed a rectal mass. Colonoscopy revealed circumferential granular involvement of the rectal mucosal surface ( $\triangleright$ Video 1 ). Histology showed a dense lymphoid infiltrate and lymphatic follicles ( $>$ Fig. 1).

Infection [3] and lymphoma were excluded ( $\$$ Fig. 2 ) and a diagnosis of rectal tonsil was made [4]. Excellent clinical and endoscopic response was achieved after a 1-month course of rectal mesalazine administered twice daily ( $\triangleright$ Fig.3). Because the lesion is benign in nature, with transformation into lymphoma being the exception [4], treatment was discontinued. The patient continued asymptomatic at 3-month clinical follow-up.

Endoscopy_UCTN_Code_CCL_1AD_2AC

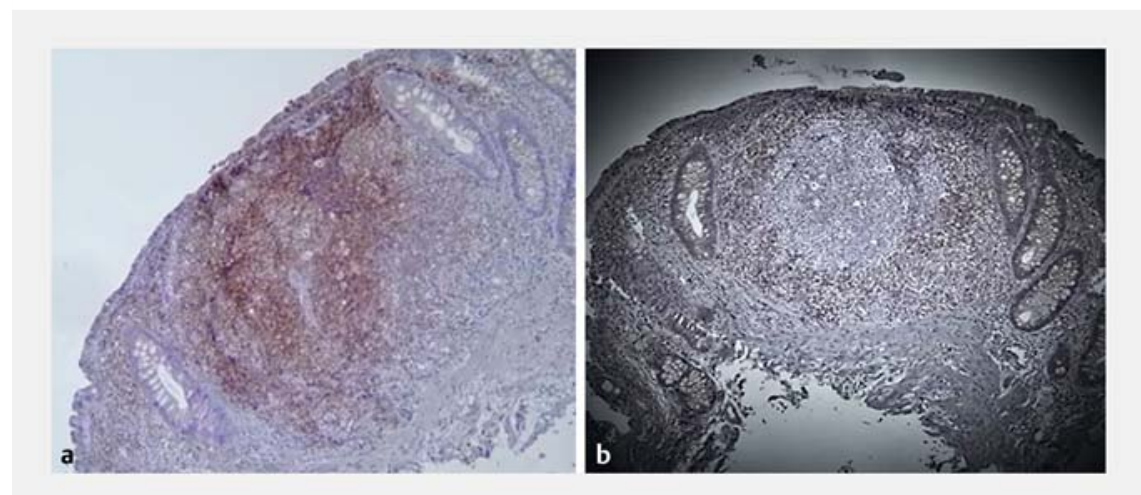

Fig. 2 Rectal mucosa of the same patient. a Lymphatic follicle positive for CD20 $(\times 10)$; b lymphatic follicle with germinal center negative for $\mathrm{Bcl} 2(\times 10)$.
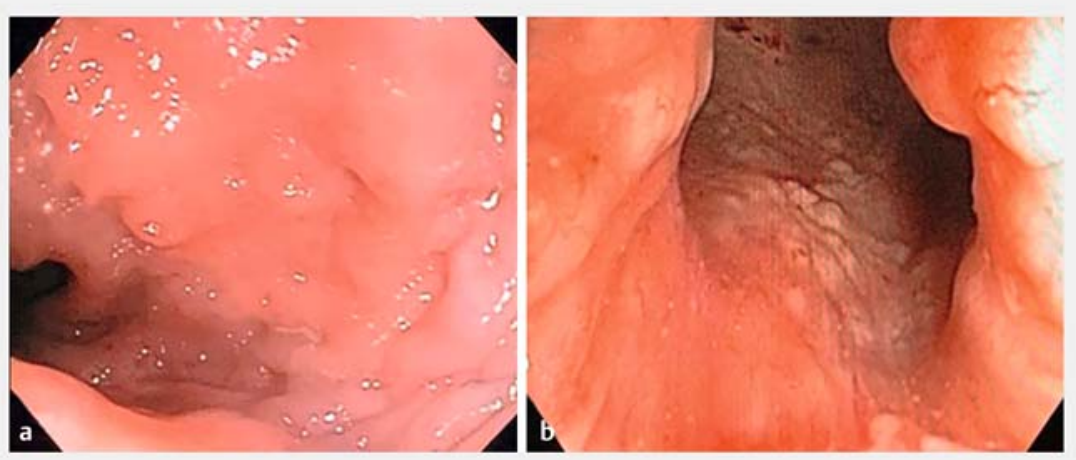

- Fig. 3 Treatment with rectal mesalazine: appearance of the rectal mucosa before treatment (a) and after treatment (b).

\section{Acknowledgments}

We acknowledge Prof. Dr. Carolina Olano (Hospital de Clínicas Uruguay) for her dedication and support in the publication of this E-Video.

\section{Competing interests}

The authors declare that they have no conflict of interest.

\section{The authors}

Ignacio Moratorio', M. Alejandra Arriola ${ }^{1}$, Ximena Pazos' ${ }^{1}$, Patricia Dorfman ${ }^{2}$, Marta Otero $^{2}$

1 Department of Gastroenterology, Hospital de Clínicas, Facultad de Medicina,

Universidad de la República, Montevideo, Uruguay

2 Department of Pathological Anatomy, Hospital de Clínicas, Facultad de Medicina, Universidad de la República, Montevideo, Uruguay 


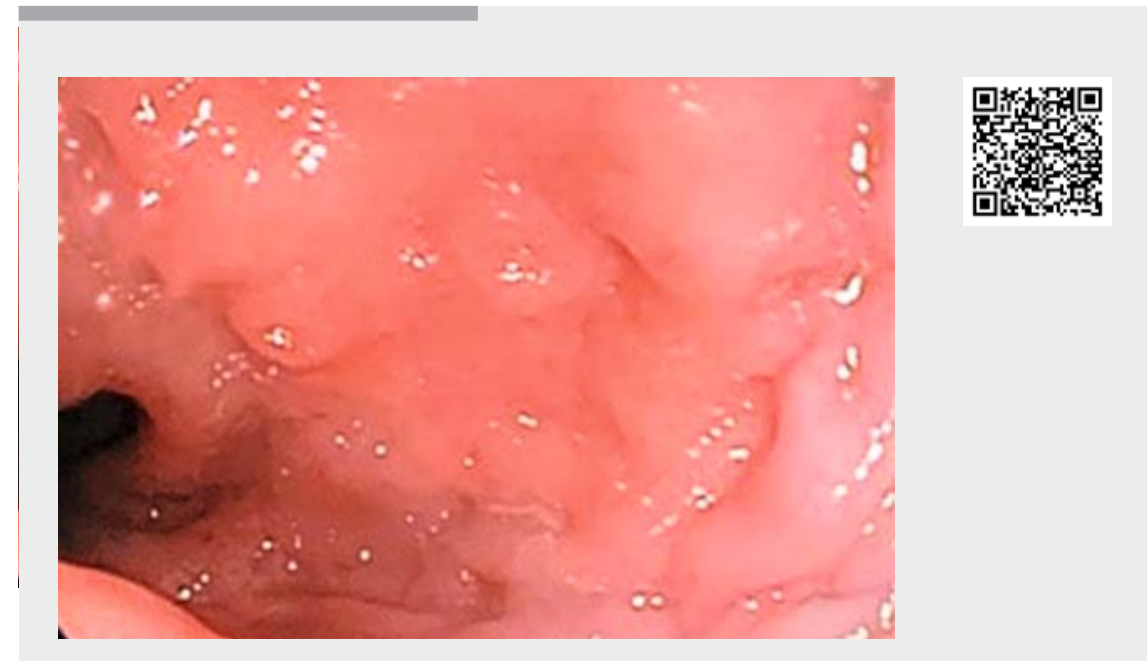

$\checkmark$ Video 1 Colonoscopic appearance of a rectal tonsil before and after treatment with mesalazine.

\section{Corresponding author}

\section{Ignacio Moratorio, MD}

Gregorio Suarez 2825/205, CP 11300

Montevideo, Uruguay

ignaciomoratorio@gmail.com

\section{Bibliography}

Endoscopy 2020; 52: E443-E444

DOI 10.1055/a-1158-8882

ISSN 0013-726X

published online 12.5 .2020

(c) 2020. Thieme. All rights reserved.

Georg Thieme Verlag KG, Rüdigerstraße 14,

70469 Stuttgart, Germany

\section{ENDOSCOPY E-VIDEOS \\ https://eref.thieme.de/e-videos}

回故 Endoscopy E-Videos is a free

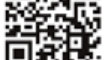
access online section, reporting on interesting cases and new

techniques in gastroenterological endoscopy. All papers include a high quality video and all contributions are freely accessible online.

This section has its own submission website at https://mc.manuscriptcentral.com/e-videos 